\title{
Endobronchial pulp-canal reamer extracted with the fibreoptic bronchoscope
}

\author{
CFC RIZZON, LC SEVERO \\ From the Hospital Moinhos de Vento, Porto Alegre, Brasil
}

The fibreoptic bronchoscope has been used to extend diagnostic and therapeutic utility beyond that of the rigid instrument. Flexible bronchoscopy has also been reported as the procedure of choice in extracting small or slender foreign bodies, which usually are lodged in segmental or subsegmental bronchi. ${ }^{1}$ The successful extraction of an aspirated pulp-canal reamer is presented.

\section{Case report}

A 45-year-old man had had an unproductive and persistent cough for two weeks, after aspiration of a pulpcanal reamer. A chest radiograph revealed the aspirated object lodged in the posterior basal segment of the lower left lobe (figure). Because the object was inaccessible to the rigid bronchoscope, the patient was referred to a surgeon with a view to thoractomy. He invited us to try to remove the foreign body before considering surgery. After local anaesthesia, a fibreoptic bronchoscope (Olympus BF-1T) was introduced through the mouth. The object was not directly visualised, but using fluoroscopy the pulp-canal reamer was grasped by standard forceps and extracted.

\section{Discussion}

Eighteen cases of extractions of various kinds of endobronchial foreign bodies by biopsy forceps have been reported. ${ }^{1-4}$ Among them four publications deal with aspirated metallic instruments. In all of them the foreign body was inaccessible to the rigid bronchoscope and fluoroscopy was used. ${ }^{1-3}$ The use of the fibreoptic bronchoscope should be considered when the foreign body cannot be removed by the rigid instrument. Opaque objects may be extracted with the aid of fluoroscopy. Fibreoptic bronchoscope extraction of foreign bodies presents less risks ${ }^{5}$ than surgical procedures.

Address for reprint requests: Dr Rizzon, Av Jeronimo de Ornellas 405/24, 90000 Porto Alegre, RS, Brasil.

Figure Radiograph showing the position of the pulpcanal reamer.

\section{References}

${ }^{1}$ Hiller C, Lerner S, Varnum $\mathrm{R}$ et al. Foreign body removal with the flexible fiberoptic bronchoscope. Endoscopy 1977;9:216-22.

${ }^{2}$ Rohde FC, Celis ME. The removal of an endobronchial foreign body with the fiberoptic bronchoscope and image intensifier. Chest 1977;72:265.

${ }^{3}$ Smith LJ, Khan MA. Role of fiberoptic bronchoscopy in removal of a foreign body. Chest 1977;72:264-5.

${ }^{4}$ Heinz GJ, Richardson RH, Zavala DC. Endobronchial foreign body removal using the bronchofiberscope. Ann Otol Rhinol Laryngol 1978;87:50-2.

${ }^{5}$ Fieselmann JF, Zavala DC, Keim LW. Removal of foreign bodies (two teeth) by fiberoptic bronchoscopy. Chest 1977;72:241-3. 